ORIGINAL ARTICLE

\title{
Epidemiology of apparent life threatening events
}

\author{
U Kiechl-Kohlendorfer, D Hof, U Pupp Peglow, B Traweger-Ravanelli, S Kiechl
}

Arch Dis Child 2004;90:297-300. doi: 10.1136/adc.2004.049452

\begin{abstract}
See end of article for authors' affiliations

.....................

Correspondence to: Prof. U KiechlKohlendorfer, Department of Paediatrics, Division of Neonatology, Innsbruck University Hospital, Anichstrasse 35, A-6020 Innsbruck, Austria; ursula.kohlendorfer@ vibk.ac.at
\end{abstract}

Accepted 9 June 2004

\begin{abstract}
Aims: To investigate the epidemiology and risk factors of apparent life threatening events (ALTE).
Methods: A prospective study enrolled all live-born infants in the Tyrol (1993-2001). Information on pregnancy, sociodemographic characteristics, child care practices, and infant's behaviour in the first four to six weeks of life was collected with a standardised questionnaire, and was available for 44184 infants. ALTE was identified from hospital admission records.

Results: During the study period 164 ALTE cases were identified, corresponding to an incidence of 2.46/ 1000 live births. In 73 of these infants no cause for the event and no comorbidity could be found (idiopathic ALTE). On average ALTE manifested ten weeks earlier than SIDS. Of various SIDS risk factors in the survey area, the prone sleeping position, smoking during pregnancy, low gestational age, profuse night sweating, and family history of infant death showed a moderate relation to the risk of overall ALTE, but only smoking maintained significance in the multivariate risk model. None of these variables was associated with idiopathic ALTE. In contrast to SIDS the frequency of ALTE did not change during the study period. None of the ALTE infants experienced SIDS later in life. Behavioural abnormalities such as feeding difficulties, episodes of pallor, cyanotic episodes, and repeated apnoea episodes were strongly associated with an increased risk of overall and idiopathic ALTE.

Conclusions: Although there are some similarities in the clinical presentation and epidemiology of SIDS and ALTE, differences clearly predominate. Accordingly, ALTE and SIDS should not be considered different manifestations of the same disease process.
\end{abstract}

$\mathrm{A}$ $\mathrm{n}$ apparent life threatening event (ALTE) is defined as "an episode that is frightening to the observer and that is characterised by some combination of apnoea (central or occasionally obstructive), colour change (usually cyanotic or pallid but occasionally erythematous or plethoric), marked change in muscle tone (usually marked limpness), choking, or gagging". ${ }^{1}$ Each year many infants with clinical features compatible with these diagnostic criteria are admitted to hospital. ${ }^{2}$ Resuscitation is sometimes necessary, ranging from mild stimulation to full cardiorespiratory support measures. Some of these infants die and may be classified as SIDS, which raises the possibility that ALTE and the sudden infant death syndrome (SIDS) are different expressions of the same disease. A number of previous studies reported that up to $12 \%$ of SIDS victims had experienced one or more prior episodes of ALTE. ${ }^{3-7}$

We performed a large prospective cohort study to examine whether there is an association between SIDS and ALTE in terms of shared risk factors and other common demographic characteristics.

\section{METHODS}

The survey area of this study is the Tyrol, a federal state in the western part of Austria with 630000 inhabitants and an area of $12650 \mathrm{~km}^{2}$. It is a mountainous region located in the Alps. Main sources of income are light industry, agriculture, and tourism. The population in the Tyrol is only Caucasian. Data on child care practices were prospectively collected four to six weeks after birth for all live-born infants in the study period between 1993 and 2001. The participation rate was 86\% among ALTE infants (141 of 164) and 66\% among controls (44 184 of 66549 ). The following variables were assessed in a standardised questionnaire completed by the infant's mother: (a) infant's data: age, sex, birth weight, and gestation; (b) sociodemographic background: maternal educational level, marital status; (c) pregnancy characteristics: mother's age at delivery, number of previous pregnancies, maternal smoking habits during pregnancy; (d) postnatal factors: infant medical history and child care practices such as usual sleeping position, feeding practices; (e) infant behaviour: apnoea, repeated cyanotic episodes, remarkably pallid, profuse sweating during night. The prospective questionnaire used in the current study is part of the public health programme in Tyrol and was approved by the appropriate committee of the local Board of Health.

In accordance with usual practice, low birth weight was defined as a birth weight $<2500 \mathrm{~g}$ and preterm delivery as $<37$ completed weeks of gestation. Maternal age at delivery was subdivided into two groups: $<23$ years and $\geqslant 23$ years; educational level was documented in years of education $(<12$ years $v \geqslant 12$ years). Smoking during pregnancy and thereafter was assessed in terms of "number of cigarettes smoked per day". The infant's usual sleeping position was classified as prone (on stomach), lateral (on side), or supine (on back). Feeding practice during the first four to six weeks of life was coded as "bottle fed", or "breast fed" if the main type of milk given was breast milk. Feeding difficulties such as frequent vomiting after feeds or difficulties with swallowing were also carefully assessed. Mothers also reported whether they had repeatedly (that is, more than once) seen their infant "turn blue", "turn pale", or "stop breathing". A minimal duration of 8-10 seconds was mentioned in the questionnaire as a crude guideline for the definition of apnoea. "Profuse sweating during sleep" was assessed when the infant's pyjamas and/or bed sheets were regularly soaked with sweat. To test for a possible genetic predisposition, parents were asked to report unexpected and unexplained deaths that had occurred in children under 1 year of age among their first and second degree relatives.

Data on all public hospital admissions of infants aged less than 1 year in the survey area were extracted from hospital computer databases (1993-2001). A search was made of various principal and also subsidiary diagnoses under which

Abbreviations: ALTE, apparent life threatening events; SIDS, sudden infant death syndrome 
such infants might be classified, and included the ICD-9 codes 798.4 (ALTE) and 786.0 and 786.9 (dyspnoea and respiratory abnormalities). In 2001 the ICD-10 classification was introduced, which no longer lists a specific ALTE code. Therefore, a search was made for R06.0 (dyspnoea), R06.8 (respiratory abnormalities, apnoea), and P28.4 (apnoea in the neonatal period). In a second step a definite classification was established by means of a critical review of the hospital medical records. To assess the incidence of ALTE the number of live births was used as the denominator. Associations between baseline variables and ALTE were analysed by means of the $\chi^{2}$ test. Relative risks were calculated by dividing the incidence of ALTE among infants with a potential risk condition by the incidence among those without. Multivariate relative risks were estimated by logistic regression modelling.

\section{RESULTS}

During the study period between 1993 and 2001 a total of 164 infants met the diagnostic criteria for ALTE, corresponding to a mean incidence of 2.46 per 1000 live births. There was no clear tendency of disease rates over the time period, especially no change parallel to the substantial drop in the SIDS rate after 1994 when the SIDS prevention programme was initiated in Tyrol (fig 1). Of note, none of the ALTE infants died from SIDS later in life. The median age-at-event for overall and idiopathic ALTE was 8 weeks compared to 18 weeks in SIDS infants $(\mathrm{p}<0.001$, Mann-Whitney $\mathrm{U}$ test). Age distributions are depicted in fig 2. Clinical comorbidity was detected in 91 of the 164 ALTE cases (55\%). In descending order of priority, disturbances of the respiratory (29\%) and the digestive tract $(22 \%)$, congenital cardiac malformations $(2 \%)$, inborn metabolic errors ( $1 \%)$, and convulsions ( $1 \%$ ) were observed. In several infants ALTE was the initial clinical presentation of severe airway infection, especially respiratory syncytial virus bronchiolitis and pneumonia. Disturbances of the digestive tract included gastro-oesophageal reflux as well as aspiration or
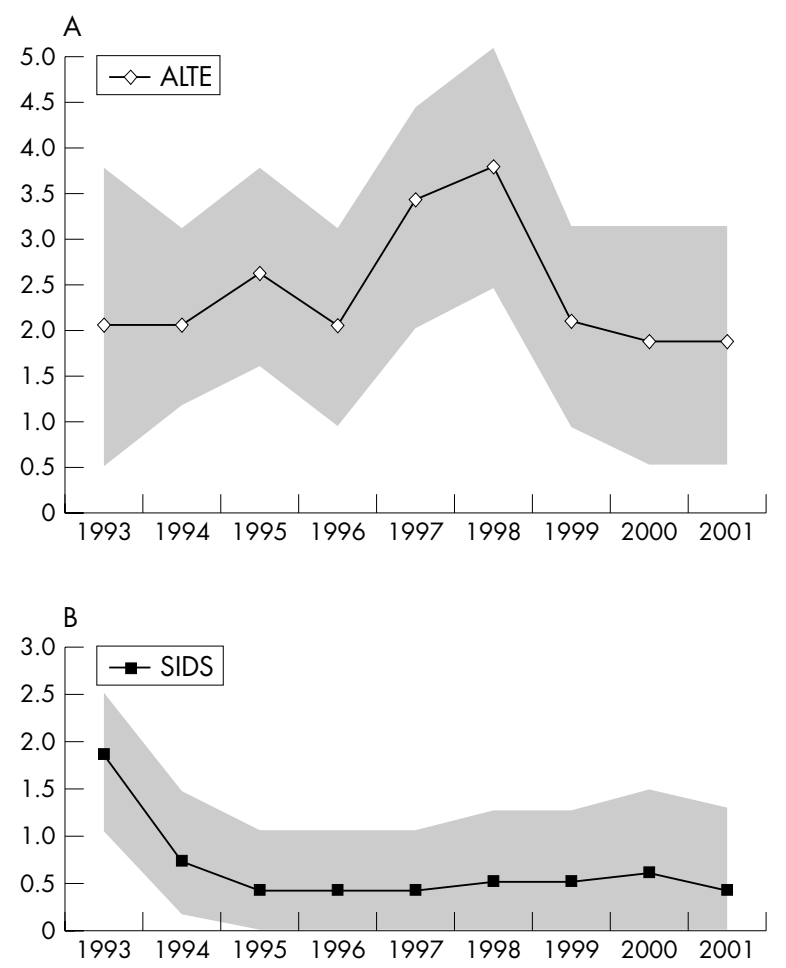

Figure 1 (A) Rates (per 1000 live births) and $95 \% \mathrm{Cl}$ of ALTE in Tyrol. (B) Rates (per 1000 live births) and 95\% Cl of SIDS in Tyrol. choking during feeding. In 73 infants no cause for the event and no concomitant disease were identified. These events were called "idiopathic ALTE".

Potential association with SIDS risk factors was tested in 141 of the 164 ALTE cases (86\%) for whom prospectively collected questionnaires were available. In the univariate analysis, ALTE was significantly associated with family history of infant death, single parenthood, profuse night sweating, as well as smoking during pregnancy (all $\mathrm{p}<0.001$ ), and less so with prone sleeping, low birth weight, or low gestational age. The latter associations lost significance once accounting for the multiple comparisons performed. In terms of absolute frequencies, the three main SIDS risk factors in the survey area (prone sleeping, lack of breast feeding, smoking in pregnancy) were much more prevalent among SIDS than ALTE infants. Of note, infant behavioural characteristics in the first weeks of life, such as repeated apnoeas and cyanotic episodes, a positive history of pallor, and feeding difficulties, were strongly related to the risk for ALTE. At least one of these characteristics was detected in about two thirds of infants who suffered an ALTE later on in life $(66.4 \% \vee 29.9 \%$ in controls; $p<0.001)$. The difference was even more pronounced when feeding difficulties were not included in the calculation $(50.7 \% v 16.9 \%$ in controls; $\mathrm{p}<0.001$ ). In a multivariate analysis allowing for all variables listed in table 1 (stepwise selection procedure with standard inclusion and exclusion criteria $\mathrm{p}_{\mathrm{E}}<0.1$ and $\left.p_{R}<0.15\right)$ the ALTE risk profile was composed of single parenthood, parent reported apnoeas, cyanotic episodes, episodes of pallor, feeding difficulties ( $p<0.01$ each), maternal smoking $(p=0.036)$, and family history of infant death $(\mathrm{p}=0.094)$ (table 2$)$.

When the analyses were restricted to cases of idiopathic ALTE, only behavioural characteristics qualified as significant risk indicators. Demographic characteristics and SIDS risk factors all did not achieve significance after accounting for the multiple comparisons performed (table 1) and did not enter the multivariate risk models (table 2).

\section{DISCUSSION}

Infants suffering from ALTE usually present with an acute and unexpected change in behaviour that alarmed the caregiver. The initial episodes can occur during sleep, when the infant is awake, or sometimes during feeding. The clinical appearance is defined by a combination of apnoea, colour change (cyanotic or pallid), marked change in muscle tone (limpness, rarely rigidity), choking, or gagging. ${ }^{1}$ Resuscitation may be necessary and range from mild stimulation to full cardiorespiratory support measures. ALTE is associated with or caused by a variety of diseases, but in $30-70 \%^{7-10}$ and $45 \%$ in our survey, the cause of the event remains undetermined and the event is then termed "idiopathic ALTE".

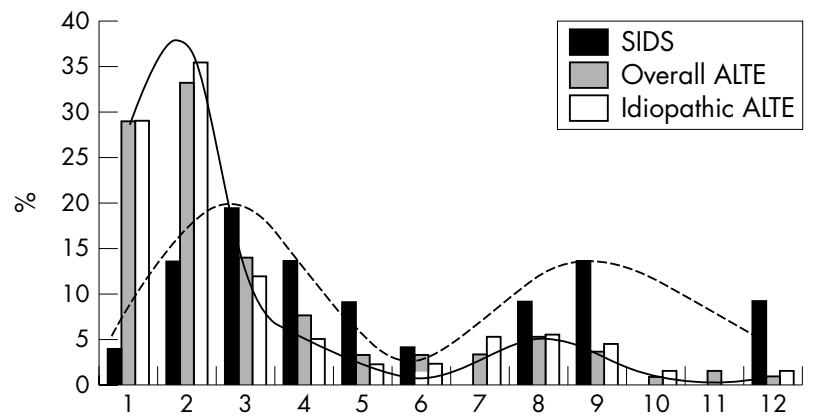

Figure 2 Age distribution of infants admitted to hospital with ALTE and those who died from SIDS, 1993-2001. 
Table 1 Association between various variables (demographic variables, infant's characteristics, SIDS risk variables, behavioural characteristics) and ALTE

\begin{tabular}{|c|c|c|c|c|c|c|c|c|}
\hline Variables & Controls (\%) & $\begin{array}{l}\text { Overall } \\
\text { ALTE (\%) }\end{array}$ & p value & RR & $\begin{array}{l}\text { Idiopathic } \\
\text { ALTE }(\%)\end{array}$ & p value & $\mathbf{R R}$ & SIDS (\%) \\
\hline \multicolumn{9}{|c|}{ Demographic variables and SIDS risk attributes } \\
\hline Male sex & 50.9 & 45.0 & 0.166 & 0.79 & 40.4 & 0.113 & 0.65 & 50.0 \\
\hline Previous pregnancies $\geqslant 2$ & 23.9 & 25.3 & 0.768 & 1.08 & 31.6 & 0.176 & 1.47 & 27.3 \\
\hline Educational level $\geqslant 12$ years $\ddagger$ & 30.0 & 20.0 & 0.144 & 0.67 & 33.3 & 0.856 & 1.11 & 15.2 \\
\hline Single parenthood & 9.6 & 23.8 & $<0.001$ & 2.93 & 16.4 & 0.089 & 1.84 & 9.5 \\
\hline Mother's age $<23$ years $\dagger$ & 11.2 & 15.0 & 0.149 & 1.40 & 14.0 & 0.490 & 1.30 & 22.7 \\
\hline Low birth weight† & 5.0 & 10.1 & 0.006 & 2.13 & 5.3 & 0.906 & 1.10 & 13.6 \\
\hline Family history infant death* & 6.1 & 14.4 & $<0.001$ & 2.59 & 12.5 & 0.044 & 2.21 & 18.2 \\
\hline Low gestational age ${ }^{*}$ & 7.4 & 13.0 & 0.018 & 1.86 & 6.0 & 0.702 & 0.80 & 19.0 \\
\hline Smoking during pregnancy* & 15.2 & 27.1 & $<0.001$ & 2.02 & 21.2 & 0.218 & 1.49 & 42.1 \\
\hline Prone sleeping position* & 4.7 & 8.6 & 0.028 & 1.92 & 10.7 & 0.033 & 2.44 & 38.1 \\
\hline No breast feeding* & 10.5 & 14.9 & 0.092 & 1.50 & 9.1 & 0.740 & 0.86 & 55.0 \\
\hline Profuse night sweating ${ }^{*}$ & 11.2 & 22.9 & $<0.001$ & 2.33 & 17.5 & 0.131 & 1.68 & 35.0 \\
\hline \multicolumn{9}{|l|}{ Behavioural characteristics } \\
\hline Repeated apnoea episodes & 1.6 & 23.5 & $<0.001$ & 18.18 & 22.8 & $<0.001$ & 18.02 & 5.9 \\
\hline Remarkably pallid & 4.0 & 15.4 & $<0.001$ & 4.30 & 14.3 & $<0.001$ & 2.95 & - \\
\hline Cyanotic episodes & 2.6 & 18.5 & $<0.001$ & 8.42 & 17.5 & $<0.001$ & 7.97 & 0.0 \\
\hline Feeding difficulties & 20.3 & 50.7 & $<0.001$ & 4.01 & 50.9 & $<0.001$ & 4.05 & 10.5 \\
\hline
\end{tabular}

Once the multiple comparisons were accounted for, a p value $<0.00357$ (marked in bold) should be considered statistically significant (Bonferroni adjustment). $\mathrm{RR}$, relative risk.

Risk factors for SIDS in the Tyrol (1993-2001): ${ }^{*} p<0.05,+p<0.10$.

$\ddagger$ Maternal educational level is available in a subgroup.

In various large population surveys, in which hospital records served as the source of information for case ascertainment, the frequency of ALTE was estimated to be between 0.46 and 10.0 per 1000 live births. ${ }^{11-14}$ The incidence of 2.46 per 1000 live births in our study fits very well into this range. Other evaluations, in which the ALTE classification relied on the parents' response to questions such as whether they observed episodes of lifelessness or unusual respiratory events (apnoea, cyanosis, irregular respiration), reported incidence rates as high as $3-6 \%{ }^{6}{ }^{15}$

In contrast to SIDS, data on potential risk factors of ALTE are sparse. So far, only two prospective studies are available, one from Sweden ${ }^{11}$ and one from Tasmania. ${ }^{16}$ In the Swedish study, epidemiological features of SIDS cases and cases of an attack of lifelessness, which comes close to our ALTE definition, were well documented, but comparable data were not available from healthy control infants in the same region. ${ }^{11}$ In the Tasmanian study the cohort cannot be regarded as representative of the general infant population, because only the one-fifth of live births with the highest SIDS risk scores were enrolled. ${ }^{16}$ Our study is the first prospectively designed and population based study to examine the epidemiology of ALTE, its potential relation to SIDS, and behavioural abnormalities.

\section{ALTE and SIDS}

The relation between ALTE and SIDS is a matter of ongoing controversy. Similarities exist in the clinical appearance of both diseases. However, there are substantial differences in SIDS and ALTE epidemiology:

(1) Intervention programmes aimed at reducing the prevalence of SIDS risk factors resulted in a substantial and sustained reduction of SIDS rates in the survey area of this study and several other countries. ${ }^{17-19}$ In contrast, over the same time period no consistent trends in the frequency of ALTE was observed (fig 1). In analogy, in Tasmania $^{20}$ and New Zealand, ${ }^{21}$ where SIDS and total postneonatal mortality dropped dramatically following the initiation of SIDS intervention programmes, rates of hospital admission for apnoea/cyanosis did not change.

(2) ALTE and SIDS, although both disorders of the first year of life, differed significantly in age-at-event, with ALTE manifesting 10 weeks earlier on average. The age distribution of both diseases in the Tyrol (fig 2) is similar to that in New Zealand. ${ }^{21}$

(3) The risk profiles for SIDS and overall ALTE showed only a modest overlap, and none of the various SIDS risk factors emerged as a significant predictor of idiopathic ALTE. In terms of absolute frequencies the three main SIDS risk variables in the survey area (prone sleeping, lack of breast feeding, smoking in pregnancy) ${ }^{19} 22$ were much more prevalent among SIDS than ALTE infants (table 1). Smoking in pregnancy was the only prominent SIDS risk condition that emerged as a significant risk predictor of

Table 2 Multivariate association between risk variables and overall and idiopathic ALTE

\begin{tabular}{|c|c|c|c|c|}
\hline Variable & $\begin{array}{l}\text { Overall ALTE } \\
\text { RR }(95 \% \mathrm{CI})\end{array}$ & p value & $\begin{array}{l}\text { Idiopathic ALTE } \\
\text { RR }(95 \% \mathrm{CI})\end{array}$ & $p$ value \\
\hline Single parenthood & $2.2(1.3$ to 3.6$)$ & 0.003 & & \\
\hline Family history of infant death & $1.7(0.9$ to 3.0$)$ & 0.094 & & \\
\hline Smoking during pregnancy & $1.6(1.1$ to 2.6$)$ & 0.036 & & \\
\hline Repeated apnoea episodes & 7.0 (3.9 to 12.3$)$ & $<0.001$ & $10.0(4.5$ to 21.8$)$ & $<0.001$ \\
\hline Remarkably pallid & $2.3(1.3$ to 4.1$)$ & 0.005 & $2.1(0.9$ to 4.9$)$ & 0.098 \\
\hline Cyanotic episodes & 4.1 (2.3 to 7.2$)$ & $<0.001$ & $3.2(1.4$ to 7.6$)$ & 0.008 \\
\hline Feeding difficulties & $2.2(1.4$ to 3.4$)$ & $<0.001$ & 2.5 (1.3 to 4.6$)$ & 0.005 \\
\hline
\end{tabular}

Relative risks (RR) and $95 \%$ confidence intervals $(95 \% \mathrm{Cl})$ were estimated from logistic regression modelling. The multivariate analyses were fitted with a forwardstepwise selection procedure allowing for all variables in table 1 except for mother's educational level which was available in a subgroup only. Seven and four variables, respectively, met the selection criteria ( $p$ value for entry: $p<0.10$; $p$ value for removal: $p<0.15$ ). 


\section{What is already known on this topic}

- SIDS prevention programmes have failed to reduce the frequency of ALTE

\section{What this study adds}

- This is the first large scale prospective population based study to examine risk factors for ALTE

- The study showed substantial differences in the epidemiology of ALTE and SIDS

- The majority of ALTE infants showed behavioural abnormalities in the first weeks of life

overall ALTE in both the unadjusted and multivariate models. Hypothetically, disturbances in the respiratory tract (29\% in our cohort) may serve as a possible causal link for the strong association between smoking and non-idiopathic ALTE. Respiratory tract infection and fever have been reported to increase the severity of prolonged expiratory apnoea. ${ }^{23}$ Southall postulated that factors that alter the normal patterns of fetal breathing (for example, maternal smoking) could influence pulmonary development, particularly with regard to alveolar function and stability, thus increasing the likelihood of prolonged expiratory apnoea. ${ }^{23}$ The association between overall ALTE and maternal smoking is also a finding of a case-cohort study from New Zealand. ${ }^{21}$ Other SIDS risk factors in Tyrol, some of which predict explained sudden death as well, ${ }^{24}$ showed a moderate association with overall ALTE (table 1) but were not significant in the multivariate risk model.

(4) Of particular note, none of our ALTE infants experienced SIDS later in life. This observation is in apparent contrast to the findings of some previous investigations among SIDS infants..$^{4-6}$ The discrepancy may be explained by the fact that in the latter studies ALTE was retrospectively assessed by the parents and less stringent criteria for ALTE were applied.

In all, our findings lend support to the standpoint that ALTE and SIDS are not different expressions of the same disease.

\section{Behavioural abnormalities in ALTE}

Remarkably, the majority of overall and idiopathic ALTE infants showed behavioural abnormalities in the first weeks of life $(66.4 \%$ and $68.4 \%$, respectively). This applies to episodes of cyanosis, repeated apnoeas, pallor, and/or difficulty with feeding. The latter finding is in accordance with the results of the Tasmanian study, in which a history of turning blue while feeding and breathing trouble while feeding were associated with the parental report of episodes of cyanosis, breathing difficulties, and hospital admission for apnoea/cyanosis. ${ }^{16}$ The Swedish study revealed that $29 \%$ of the infants with attacks of lifelessness had more than one apnoeic spell during the three day period around the attack, indicating a period of respiratory instability, but only $12 \%$ had such spells later on. ${ }^{11}$ In all, the large percentage of behavioural abnormalities is a striking feature and may be a basis for a better understanding of the mechanisms underlying ALTE and a clue for early identification of risk infants for potential future prevention programmes.

\section{Summary}

In our prospective evaluation a substantial proportion of infants with ALTE showed behavioural abnormalities such as repeated apnoeas, pallor, cyanotic episodes, and/or feeding difficulties prior to the ALTE event. Although there are some similarities in the clinical presentation and epidemiology of SIDS and ALTE, differences clearly predominate. Accordingly, ALTE and SIDS should not be considered different manifestations of the same disease process, nor can SIDS prevention programmes be expected to considerably lower the frequency of ALTE.

\section{Authors' affiliations}

U Kiechl-Kohlendorfer, Department of Paediatrics, Division of Neonatology, University of Innsbruck Medical School, Innsbruck, Austria D Hof, U Pupp Peglow, Department of Paediatrics, Division of General Paediatrics, University of Innsbruck Medical School, Innsbruck, Austria B Traweger-Ravanelli, IMAD Medical Data Registry, Innsbruck, Austria S Kiechl, Department of Neurology, University of Innsbruck Medical School, Innsbruck, Austria

Competing interests: none declared

\section{REFERENCES}

1 National Institutes of Health Consensus Development Conference on Infantile Apnea and Home Monitoring. Consensus Statement. Pediatrics 1987;79:292-9.

2 Gray C, Davies F, Molyneux E. Apparent life-threatening events presenting to a pediatric emergency department. Pediatr Emerg Care 1999;15:195-9.

3 Brooks JG. Apparent life-threatening events and apnea of infancy. Clin Perinatol 1992;19:809-38

4 Kahn A, Blum D, Hennart P, et al. A critical comparison of the history of sudden-death infants and infants hospitalized for near-miss for SIDS. Eur J Pediatr 1984;143:103-7.

5 Norvenius S. Sudden infant death syndrome in Sweden in 1973-1977 and 1979. Acta Paediatr (Suppl) 1987;333:1-138.

6 Platt MW, Blair PS, Fleming PJ, et al. A clinical comparison of SIDS and explained sudden infant deaths: how healthy and how normal? Arch Dis Child 2000;82:98-106.

7 Kahn A. Recommended clinical evaluation of infants with an apparent lifethreatening event. Consensus document of the European Society for the Study and Prevention of Infant Death, 2003. Eur J Pediatr 2004;163:108-15.

8 Gershan WM, Besch NS, Franciosi RA. A comparison of apparent lifethreatening events before and after the back to sleep campaign. WMJ 2002; 101:39-45

9 Kahn A, Montauk L, Blum D. Diagnostic categories in infants referred for an acute event suggesting near miss SIDS. Eur J Pediatr 1987; 146:458-60.

10 Farrell PA, Weiner GM, Lemons JA. SIDS, ALTE, apnea, and the use of home monitors. Pediatr Rev 2002;23:3-8.

11 Wennergren G, Milerad J, Lagercrantz $\mathrm{H}$, et al. The epidemiology of sudden infant death syndrome and attacks of lifelessness in Sweden. Acta Paediatr 1987;76:898-906

12 Polberger S, Svenningsen NW. Early neonatal sudden infant death and near death of fullterm infants in maternity wards. Acta Paediatr 1985;74:861-6.

13 Sunkaran K, McKenna A, O'Donnel M, et al. Apparent life-threatening prolonged infant apnea in Saskatchewan. West J Med 1989;150:293-5.

14 Davis N, Bakke K. Evaluation of a home apnea monitoring program. Perinatol Neonatol 1983;7:15,18.

15 Mandell F. Cot death among children of nurses. Observations of breathing patterns. Arch Dis Child 1981;56:312-14.

16 Ponsonby AL, Dwyer T, Couper D. Factors related to infant apnoea and cyanosis: a population-based study. J Paediatr Child Health 1997;33:317-23.

17 Markestad T, Skadberg B, Hordvik E, et al. Sleeping position and sudden infant death syndrome (SIDS): effect of an intervention programme to avoid prone sleeping. Acta Paediatr 1995;84:375-8

18 Willinger M, Hoffman HJ, Hartford RB. Infant sleep position and risk for sudden infant death syndrome: report of meeting held January 13 and 14 1994, National Institutes of Health, Bethesda MD. Pediatrics 1994;93:814-19.

19 Kiechl-Kohlendorfer U, Pupp Peglow U, Kiechl S, et al. Epidemiology of sudden infant death syndrome (SIDS) in the Tyrol before and after an intervention campaign. Wien Klin Wochenschr 2001;113:27-32.

20 Ponsonby AL, Dwyer T, Couper D. Sleeping position, infant apnea, and cyanosis: a population-based study. Pediatrics 1997;99:1-7.

21 Mitchell EA, Thompson JMD. Parental reported apnoea, admissions to hospital and sudden infant death syndrome. Acta Paediatr 2001;90:417-22.

22 Kohlendorfer U, Kiechl S, Sperl W. Sudden infant death syndrome: risk factor profiles for distinct subgroups. Am J Epidemiol 1998;147:960-8.

23 Southall DP. Role of apnea in the sudden infant death syndrome: a personal view. Pediatrics 1988;81:73-84.

24 Leach CEA, Blair PS, Fleming PJ, et al. Epidemiology of SIDS and explained sudden infant deaths. Pediatrics 1999;104:1-10. 